\title{
THE OCCULT BLOOD TEST
}

\author{
By Kenneth J. Gurling, M.D., M.R.C.P. \\ Medical Registrar, King's College Hospital
}

The original occult blood tests were designed for forensic purposes, Schonbein and van Deen using a chemical test with guaiacum which was more sensitive than the older. Teichmann's haemin crystal test. Subsequently similar chemical methods were widely used and in 1893 Weber described his version of the guaiacum test for detecting occult blood in the faeces. Boas first made extensive use of this method at the end of the last century, and in I901 emphasized the importance of detecting occult haemorrhage from the intestine as a diagnostic measure.

\section{Types of Test}

The methods at present in use depend on either chemical or spectroscopic examination of a suitable extract. There are many chemical methods in addition to that described by Weber. The benzidine test was devised by the Adlers in 1904 and modified, in 1906, by Schlesinger and Holst, whose technique, or that evolved by Gregersen, is probably used most of all. Other methods, the relative sensitivity of which will not be considered, include Meyer's alkaline phenolphthalein test, the orthotolidine test of Rutton and Hardisty, and techniques using pyramidon and aloin. All such methods depend on a change in colour of the reagent after oxidation, this being facilitated by the peroxidase activity of iron-containing derivatives of haemoglobin, which is not destroyed by boiling.

The spectroscopic tests, as described by Snapper (1916) and Ryffel, are of more recent development, and depend on the detection of the typical absorbtion bands of acid haematin or porphyrins.

\section{Concerning their Sensitivity}

There have been many reports on the relative sensitivity of the various tests with conflicting conclusions, but it is certain that the chemical are more sensitive than the spectroscopic tests (Ryffel and Payne, 1923).

Although positive reactions with the guaiacum test may be obtained with blood in a one in eight million dilution with water, this is of no real significance since the presence of organic matter greatly decreases this sensitivity, and when blood is freshly added to faeces a concentration of one in 2,500 may be necessary. This sensitivity is further diminished by the progressive reduction in the peroxidase activity of free blood by digestion, and possibly by abnormalities of the intestinal secretions. Constipation may decrease, and diarrhoea increase, the likelihood of a positive result because of this, and examination of the faeces after a dose of castor oil has been advised (Kirschen et al., 1942). Both pus and iodides in the specimen can in theory lead to positive results, but the activity of the former may be destroyed by boiling and the practical importance of the latter is slight.

Iron medicines taken orally do not give rise to false positive reactions, and indeed occult blood tests can be used to distinguish between melaena and discoloration of the faeces due to iron, but the detection of spectroscopic bands is made more difficult (Ogilvie, 1927, Schwartz and Vil, r947).

The spectroscopic tests, being the less sensitive, should be complementary to the chemical ones but the significance of a positive result is less open to doubt. When the spectrum of acid haematin is obtained it is certain that blood is present in fair quantity, and iron free porphyrins may be presento even when haematin is absent. There is a rare chance that porphyrins may be present in faeces due to liver or metabolic disorders, and they may. be found in meconium. It is possible for the absorbtion bands of porphyrins to be present for many days after a single haemorrhage. Detection of these spectroscopic bands is made easier if chlorophyll containing vegetables are excluded.

In connection with occult blood tests by far the most important fact to ascertain is the actual quantity of blood needed to give a positive result and whether there is any likelihood of obtaining spontaneously false results. With healthy subjects on a normal diet the spectroscopic test is negative, but chemical tests, other than Gregersen's, the sensitivity of which has been reduced, give between 30 per cent. and 70 per cent. of positive results according to the amount of meat eaten. With a strict diet for four days previously, a negative result should be obtained with a healthy subject (Bell, 1923, Ogilvie, 1927). It is necessary to ingest at least $\mathrm{I} \mathrm{ml}$. of blood, and most often $3 \mathrm{ml}$. or more, before positive chemical tests result, and this has been repeatedly confirmed (Abrahams 1923, Bell, 1923, Kirschen et al., 1942, Kiefer, 1934). This is more than could be accounted for by the usual degree of bleeding from the gums, nasal polyp or swallowed blood-streaked sputum. The chemical tests are not, therefore, in theory too sensitive and any such objection is unwarranted. 


\section{The Present Investigation}

During the year Oetober' 1947 to October 1948, occult blood tests were done on the faeces of $3 \mathbf{I} 6$ patients at King's College Hospital. The methods used were the benzidine test and Snapper's spectroscopic test as described by Harrison (1949), the examination being made in the Chemical Pathology Department. For three days preceding the collection of specimens a diet free from meat, chlorophyll or iron medicines was followed, and the teeth were cleaned only with a soft brush. No markers such as charcoal or carmine were used and specimens were obtained, as a rule, on three successive davs after a purgative. If insufficient material was sent the spectroscopic test was omitted.

The diagnosis has been reviewed after two years in 3.02 cases ( 96 per cent.), the remainder being discarded because of incomplete records. A total of $\mathrm{I}, 780$ examinations was made, 906 chemical and 86. spectroscopic. A positive result was obtained on one or more occasions in II7 cases (39 per cent.), whilst ${ }_{185}$ cases $(6 \mathrm{I}$ per cent.) remained negative. These results, and their clinical significance, will be discussed under the following headings :

\section{Peptic Ulcer}

This constituted the largest group of $\mathrm{I}_{32}$ patients, I IO of whom were considered to have active ulcers, and 22 ulcers which were, at the time of the test, considered clinically and radiologically healed. The results are shown in Table $\mathbf{I}$, and although the numbers are small it appears that about half ( 48 per cent.) of active peptic ulcers will give a positive test, but that even when there is a chronic ulcer unresponsive to treatment, there may be no detectable haemorrhage. Hence it is not possible to assess healing by relying on the occult blood test, and, indeed, a negative result may follow the demonstration of an oozing ulcer at gastroscopy. Previous series have shown that from as few as per cent. (Setala and Telkka, I 950 ), to 47.3 per cent. (Heinänen, I938) of benign ulcers give positive results, and Moynihan also mentioned a figure of 50 per cent. in 1912 .

\section{Gastric Carcinoma}

There were 22 patients with this condition, and positive results were more frequent, 18 (82 per cent.) having detectable occult haemorrhage. In addition the majority gave persistently positive reactions, 12 giving 3 or more, 3 cases only 2 , and the other 2 patients one positive specimen.

Bleeding from a fungating or deeply ulcerating growth is much more likely to be continuous and severe than from a small benign ulcer which may be in a stage of healing, and the incidence of
TABle 1

\begin{tabular}{|c|c|c|}
\hline \multicolumn{3}{|c|}{$\begin{array}{l}\text { Presence of ulcer confirmed at operation or by } \\
\text { gastroscopy : } 65 \text { cases }\end{array}$} \\
\hline & $\begin{array}{l}\text { Faecal Occult } \\
\text { Blood Positive }\end{array}$ & $\begin{array}{l}\text { Faecal Occult } \\
\text { Blood Negative }\end{array}$ \\
\hline Gastric Ulcer & I 8 & 16 \\
\hline \multirow[t]{2}{*}{ Duodenal Ulcer } & 18 & 13 \\
\hline & $36\left(56^{\circ}\right)$ & $29\left(44_{i 0}^{\circ}\right)$ \\
\hline \multicolumn{3}{|c|}{$\begin{array}{l}\text { Ulcer demonstrated radiologically, but not } \\
\text { confirmed by laparotomy or gastroscopy : } \\
45 \text { cases }\end{array}$} \\
\hline Gastric Ulcer & 5 & 14 \\
\hline \multirow[t]{2}{*}{ Duodenal Ulcer } & 12 & 14 \\
\hline & $17(38 \%)$ & $28(62 \%)$ \\
\hline \multicolumn{3}{|c|}{$\begin{array}{c}\text { Ulcer considered, on clinical and } \\
\text { grounds, to be healed }\end{array}$} \\
\hline Gastric Ulcer & $\mathbf{I}$ & 7 \\
\hline \multirow[t]{2}{*}{ Duodenal Ulcer } & $\circ$ & 14 \\
\hline & I $(5 \%)$ & $21\left(95_{0}^{\circ}\right)$ \\
\hline
\end{tabular}

Table showing results of faecal occult blood tests iథ 65 patients with chronic peptic ulcer.

persistent positives in gastric neoplasms is significant (Boas, 1914, Usobiaga, 1948). But negative results, as with benign ulcers, may mean nothing as the following two cases demonstrated :

I. A man suffering from epigastric pain was found to have a malignant ulcer, confirmed by laparatomy. Although the aspirated stomach contents contained blood, the faecal occult blood tests were subsequently negative.

2. An old lady, admitted because of cataract, was found to be anaemic but had negative occult blood tests on three occasions in 1948 . She was readmitted for further eye operations in 1950 , but had begun to vomit and told of vague dyspepsia for over a year. At laparotomy an inoperable, ulcèrating, gastric carcinoma was found, and in retrospect the earlier anaemia was probably attributable to this.

\section{Other Neoplasms of the Intestine}

The results of faecal occult blood tests in patients with various neoplasms of the alimentary tract distal to the stomach are shown in Table 2, and the fact that the occult blood test was less frequently used in the diagnosis of these lesions than radiological examination probably explains the relatively few patients in this group. The 
extreme value of detecting occult haemorrhage from a carcinoma of the caecum is apparent, and it is here that X-rays are liable to be of little assistance, particularly when the presenting sign is often anaemia. As high a proportion as 92.5 per cent. of tumours of the intestine have been reported to give rise to positive occult blood tests in a larger series (Dahl-Iversen and Nissen, I930). The reason why neoplasms of the pancreas should give positive results without actual bowel involvement is uncertain, but has also been reported by Ryffel (1928).

\begin{tabular}{l|c|c}
\hline \multicolumn{1}{c|}{ TabLE 2 } \\
\hline Site & $\begin{array}{c}\text { Faecal Occult } \\
\text { Blood Positive }\end{array}$ & $\begin{array}{c}\text { Faecal Occult } \\
\text { Blood Negative }\end{array}$ \\
\hline Caecum & 5 & 0 \\
Colon & 2 & I \\
Pancreas & 4 & I \\
Rectum & 0 & I \\
Gallbladder & 0 & I \\
\hline
\end{tabular}

Table showing results of faecal occult blood tests in I 5 patients with various neoplasms affecting the alimentary tract distal to the stomach.

\section{Anaemia}

Occult blood tests were carried out on $3 \mathrm{I}$ patients presenting with anaemia, which was, except in three cases, of the microcytic type, possibly due to chronic blood loss. The results are shown in Table 3. The elimination of chronic blood loss from a silent bowel lesion is a routine in the diagnosis of microcytic anaemia, and in no condition is a positive result of such significance. Four of the 5 cases of carcinoma of the caecum presented with anaemia, and it is still possible that the 3 examples of iron deficiency anaemia with positive results may, in fact, have a more serious condition, as the following history will show :

TABLE 3

\begin{tabular}{|c|c|c|}
\hline $\begin{array}{l}\text { Aetiology of } \\
\text { the Anaemia }\end{array}$ & $\begin{array}{l}\text { Faecal Occult } \\
\text { Blood Positive }\end{array}$ & $\begin{array}{l}\text { Faecal Occult } \\
\text { Blood Negative }\end{array}$ \\
\hline $\begin{array}{l}\text { Iron Deficiency } \\
\text { Menorrhagia } \\
\text { Haematemesis } \\
\text { (acute ulcer) } \\
\text { Diaphragmatic } \\
\text { Hernia } \\
\text { Toxic (Empyema) } \\
\text { Pernicious } \\
\text { Anaemia } \\
\text { Leukaemia } \\
\text { Carcinoma of } \\
\text { Stomach } \\
\text { Carcinoma of } \\
\text { Caecum }\end{array}$ & $\begin{array}{l}3 \\
0 \\
0 \\
2 \\
0 \\
2 \\
1\end{array}$ & $\begin{array}{r}10 \\
2 \\
2 \\
0 \\
1 \\
1 \\
0 \\
1 \\
0\end{array}$ \\
\hline
\end{tabular}

Table showing results of faecal occult blood tests in 3 I cases clinically presenting as anaemia.
A middle-aged man was admitted to hospital in I 947 with $\mathrm{Hb} .48$ per cent., at which time a barium meal was reported as normal, and a test meal was within normal limits. Three positive occult blood tests were obtained. In spite of a response to iron medicines he again developed a microcytic anaemia in I949, when an abdominal mass was palpable and proved to be an inoperable, caecal neoplasm.

Misleading results were obtained in 2 of 3 cases of pernicious anaemia who temporarily failed to respond to one brand of liver injections, and who subsequently improved. The association of anaemia with diaphragmatic hernia is quite eommon, and one of the two cases had an ulcer at the level of the diaphragm.

\section{Other Positive Results}

This miscellaneous group included 3 cases of ulcerative colitis, the diagnosis of which was at first in doubt; another gave a negative result. One of 4 patients with diverticulitis showed a positive result, and other positive reactions occurred with Henoch's purpura, oesophageal ulceration, hook-worm infestation, alcoholic gastritis and undiagnosed melaena probably due to cirrhosis. There remained a small number of cases in which false positives were obtained; they include thyrotoxicosis with diarrhoea, hyperten sion, unexplained loss of weight, dysphagia due t - laryngeal stenosis and abdominal pain for which no cause was found. They were eleven in number and were under 10 per cent. of the II 7 patients who gave positive occult blood tests.

\section{Other Negative Results}

Functional dyspepsia $\mathrm{I} 6$

Nervous diarrhoea 5

Spastic colon

Renal pain

5

Tabetic crises

Cholecystitis

Neuroses

Undiagnosed pain 5

Entirely negative results were given by 185 patients, of whom 65 (35 per cent.) were considered to have an active, gastro-intestinal lesion capable of causing occult haemorrhage, the majority peptic ulceration.

In the differential diagnosis of abdominal pain and diarrhoea such findings are undoubtedly of value, and the benign nature of a puzzling $\mathrm{X}$-ray, such as a stricture of the ileum or diverticulum of the caecum, can sometimes be assumed. There was also a variety of conditions such as sarcoidosis, fibrositis, diabetes, myelomatosis and aortic aneurysm in which occult blood tests appear to have been used as a routine to exclude a remotely possible intestinal lesion without the bother of a barium meal or enema. However, a negative result has nothing like the diagnostic significance of a positive one. 


\section{Clinical Significance}

The proportion of cases which have a misleading negative occult blood test when a lesion was demonstrated by other means, 35 per cent., is much higher than the proportion of similar ' false' positives, which is 9 per cent. This is to be expected since it has been shown that more than a trace of blood must be lost to give a positive benzidine reaction, and that there is often an unexplained variation in this quantity from person to person. Similarly the amount of blood that must be ingested to produce a tarry motion varies from 50 to $\mathrm{r} 10 \mathrm{ml}$. There was considerable agreement between the benzidine and spectroscopic tests, the latter appearing to be very little less reliable since in only two instances were they negative when the chemical test was positive.

The bands of acid haematin were present on seventeen occasions when no evidence of porphyrins was obtained, but there was no correlation between this and the site of the lesion in the intestinal tract.

No evidence has been obtained that the benzidine test is too sensitive or that bleeding gums or other extraneous haemorrhage will give distorted results. It seems probable, however, that bleeding might be detected more often if more than three specimens were examined at a time. This analysis of a year's routine occult blood tests clearly demonstrates that this method of examination, though time consuming if properly carried out, provides much helpful information, and is well worth retaining in the repertoire. As with other laboratory tests its significance in individual cases can only be assessed in association with the history, physical examination and radiographs.

\section{Conclusion}

In an unselected series of occult blood tests there was a 90 per cent. chance that a gastrointestinal lesion was present when a positive result was obtained, but in only 65 per cent. of cases which gave negative results was there reasonable certainty that no such lesion existed.

Thanks are due to Professor C. H. Gray, in whose laboratory the tests were done, and to Dr. R. S. Bruce Pearson for their assistance.

\section{BIBLIOGRAPHY}

ABRAHAMS, A. (1923), Guy's Hosp. Rep., 73, I 37.

BELL, J. R. (1923), Ibid., 73, 20.

BOAS, I. (1901), Deutsche med. Wchnschr., 20.

BOAS, I. (1914); 'Die Lehre v.d. Okkulten Blutungen', Leipzig.

DAHL-IVERSEN, E., and NISSEN, N. I. (1930), Hospitalstitende, $73,543$.

HARRISON, G. A. (1949), 'Chemical Methods in Clinical Medicine,' 3rd edition, Churchill.

HEINANEN, N. (1938), Acta, soc. med. Fenn. Duodec., 25.

KIEFER, E. D. (1934), Amer. F. Surg., 25, 530.

KIRSCHEN, M., SORTER, H., and NECHELES, H. (I942), Amer. F. Digest Dis., 9, 154.
MOYNIHAN, A. G. (1912), 'Duodenal Ulcer,' 2nd edition Saunders.

OGILVIE, A. G. (1927), Brit. med. .., i, 755.

RYFFEL, J. H. (1928), Lancet, ii, 1353.

RYFFEL, J. H., and PAYNE, W. W. (1923), Guy's Hosp. Rep., 73, $13 \mathrm{I}$.

SETALA, A., and TELKKA, A. (1950), Ann. med. int. Fenniae, 39, II3.

SCHWARTZ, S. O., and VIL, C. S. (1947), 7. Lab. and Clin. Med., 32, $18 \mathrm{r}$.

USOBIAGA, E. (1948), Rer. espan. enferm. ap. digest. y nutricion, 7. 416 . 